\title{
Sorafenib induces apoptosis and autophagy in prostate cancer cells in vitro
}

\author{
ANDERS ULLÉN ${ }^{1,2^{*}}$, MARIANNE FARNEBO $^{1 *}$ LENA THYRELL $^{1}$, \\ SALAH MAHMOUDI $^{1}$, PEDRAM KHARAZIHA ${ }^{1}$, LENA LENNARTSSON $^{1}$, \\ DAN GRANDÉR $^{1}$, THEOHARIS PANARETAKIS ${ }^{1}$ and STEN NILSSON ${ }^{1,2}$ \\ ${ }^{1}$ Department of Oncology-Pathology, Cancer Centrum Karolinska, Karolinska Institutet; \\ ${ }^{2}$ Radiumhemmet, Karolinska Sjukhuset, 17176 Stockholm, Sweden
}

Received January 12, 2010; Accepted March 2, 2010

DOI: 10.3892/ijo_00000648

\begin{abstract}
The multiple tyrosine kinase inhibitor sorafenib has recently demonstrated clinical effects in patients with androgen-independent prostate cancer. These observations provided the rational for investigating the anti-tumoral properties of this compound on prostate cancer cell lines at the molecular level. Two hormone refractory (PC3 and DU145) and one hormone responsive cell line (22Rv1) were used. By use of a panel of cell biology techniques such as immunoblotting, flow cytometry and immunocytochemistry, effects on the MAPK pathway and induction of apoptosis and autophagy were evaluated. We demonstrate that sorafenib reduced cell viability in a dose-dependent manner, induced apoptosis and inactivated the MAPK pathway. Moreover, we show for the first time, that sorafenib treatment of prostate cancer cells also induces cellular autophagy. This feature is in accordance with the anticancer potential of sorafenib and adds another important effector mechanism of this compound. These observations may open potentially interesting treatment combinations that may augment the effect of sorafenib, either by drugs that promote autophagy such as the rapalogues, or by combining sorafenib with compounds that specifically inhibit the autophagic process.
\end{abstract}

\section{Introduction}

Patients with metastatic androgen-independent prostate cancer (AIPC) have poor prognosis with few therapeutic options, all of which are palliative. Recently, Tannock et al demonstrated that treatment with docetaxel improved survival as compared

Correspondence to: Dr Anders Ullén, Radiumhemmet, Karolinska University Hospital Solna, 17176 Stockholm, Sweden

E-mail: anders.ullen@karolinska.se

*Contributed equally

Key words: prostate cancer, sorafenib, apoptosis, autophagy to mitoxantrone. Docetaxel delivered every 3rd week in combination with low-dose prednisone is now considered standard treatment for this patient group (1). Nevertheless, the median improvement in survival is limited to 2-3 months with progression being inevitable and thus the search for more efficient treatments that can stabilize or slow the progression of AIPC is continued. Targeting of molecules in cell signaling pathways that are critical for prostate cancer specific survival has been suggested as useful treatment strategies. Receptor tyrosine kinases (RTKs), act as targets for many growth factors and consequently a number of small molecule RTK-inhibitors with varying inhibiting profiles have been developed during the last years (2). Their usefulness within the field of urologic oncology is by far most evident for renal cell carcinoma; a disease previously considered resistant to systemic treatment (3). The potential clinical benefit of targeted therapy for AIPC include drugs that affect neo-vascularisation, critical cell growth pathways and survival signaling cascades, such as BAY 439006 (sorafenib) (4) and SU11248 (sunitinib) (5).

Sorafenib is an orally administered compound with inhibiting properties on RAF kinases including Raf-1 and BRAF which are members of the RAF/MEK/ERK signaling pathway. Sorafenib also displays significant inhibition of a number of RTKs involved in neo-angiogenesis and tumor progression including vascular endothelial growth factor receptor (VEGFR)-2 and VEGFR-3, platelet derived growth factor receptor $\beta$ (PDGFR- $\beta$ ), Flt-3 and c-KIT (4). Sorafenib has been suggested for the treatment of AIPC for several reasons: i) angiogenesis has an important role for the progression of prostate cancer and angiogenic factors such as VEGF are often elevated in AIPC compared to normal tissues $(6,7)$, ii) the Ras/Raf/mitogen-activated protein kinase/ERK signaling pathway may be deregulated in AIPC (8-10) and iii) sorafenib has shown activity in preclinical tumor xenograft models (4).

During the last year, three independent phase II trials have evaluated the effect of sorafenib in AIPC (11-13). A common feature for these monotherapeutic trials is that a fraction of patients responded by stable disease or better, as defined by RECIST or PSA-response criteria. However, Dahut et al highlighted that PSA may not be an adequate biomarker for monitoring clinical sorafenib treatment effects since discordant radiographic and PSA responses were observed in several 
patients (12). In addition, Chi et al specifically noted that 10/16 patients presented with post-discontinuation PSA declines of $7-52 \%$, which may be caused by a sorafenibinduced reversion of hormone sensitivity (14). The current general interest in tyrosine kinase inhibitor (TKI) treatment of AIPC and the observed clinical effects recently reported of sorafenib stimulated us to perform this study, which aimed to explore and characterize the molecular effects of sorafenib treatment on prostate cancer cells in vitro.

\section{Materials and methods}

Cell lines and culture conditions. The human, hormone refractory, metastatic prostate carcinoma cell lines DU145 and PC3 (15) as well as the hormone responsive 22Rv1 cell line (16) were cultured in $5 \mathrm{ml}$ dishes (Falcon) with RPMI1640 (Gibco). Glutamine (2 mM) (Gibco), 10\% fetal calf serum (Life Technologist) was added to the media. The cells were kept in a $37^{\circ} \mathrm{C}$ incubator with humidified air and $5 \% \mathrm{CO}_{2}$. The culture medium was changed two times a week. Cells were removed from the dishes by treatment trypsin-EDTA (Sigma, USA). Cell lines were obtained from American Type Culture Collection (ATCC, USA).

Preparation of sorafenib. Sorafenib was provided by Bayer HealthCare Pharmaceuticals, Inc. (Wayne, NJ, USA). Sorafenib was dissolved in DMSO and final dosing solutions were prepared on the day of use from a stock solution. A concentration range of $1-50 \mu \mathrm{M}$ was typically used in the different experiments.

Fluorometric microculture cytotoxic assay (FMCA). The FMCA method was adopted from Larsson et al (17). On day one, $200 \mu \mathrm{l} /$ well of the tumor cell preparation $(10,000$ cells/ well) were seeded in triplicates into 96 well microtiter plates. Thus, the tumor cells were allowed to attach to the bottom of the plate before the drugs were added. The culture plates were then incubated at $37^{\circ} \mathrm{C}$ in humidified atmosphere containing $95 \%$ air and $5 \% \mathrm{CO}_{2}$. At the end of $72 \mathrm{~h}$ incubation, the culture medium was washed away, the 96 well plates rinsed three times in phosphate buffer saline $\mathrm{pH} 7.4$ and followed by addition of $200 \mu \mathrm{l} /$ well of physiological buffer containing $10 \mu \mathrm{g} / \mathrm{ml}$ fluorescence-diacetate. After incubation for $30 \mathrm{~min}$ at $37^{\circ} \mathrm{C}$, the fluorescence from each well was read in a Fluoroscan 2 (Lab-systems OY, Helsinki, Finland). Technically, the fluorescence generated by hydrolysis of fluorescence-diacetate to flourescein by viable cells is measured. The dose-response experiments were done at least three times for each cell line.

Phosphorylation studies. Cells were starved in serum deficient medium for $24 \mathrm{~h}$ prior to the substitution of FBS enriched medium in the absence or presence of the indicated concentrations of sorafenib. The cells were incubated for additional 10-30 min, depending on the time ERK phosphorylation peak is reached for each cell line. Following this incubation time, cell lysates were collected in $2 \mathrm{X}$ loading buffer containing $\beta$ mercaptoethanol, sonicated and separated by SDS-PAGE (Invitrogen, CA) on 4-12\% gradient gels under denaturing conditions and transferred onto PDVF membranes (Amersham). After blocking in 5\% BSA (Sigma-Aldrich, St. Louis,

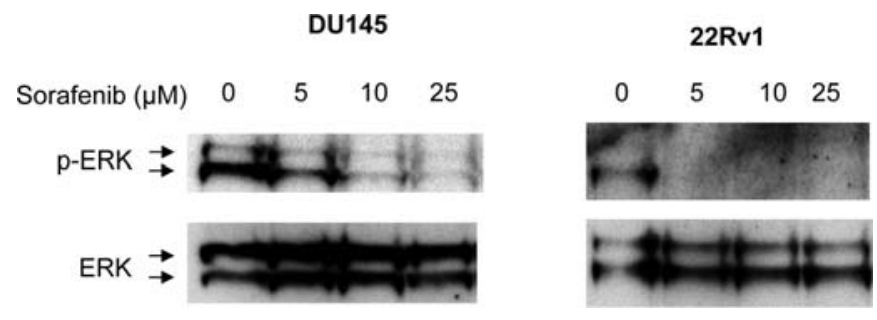

Figure 1. Sorafenib inhibits ERK phosphorylation in prostate cancer cell lines. Western blot analysis of phosphorylated ERK (p-ERK) and total ERK (loading control) protein levels in DU145 and 22Rv1 cells treated with sorafenib at the indicated concentrations for $4 \mathrm{~h}$. The cells were serum-starved overnight prior to sorafenib treatment.

MO), the PVDF filters were incubated overnight at $4^{\circ} \mathrm{C}$ with the primary antibody anti-phospo-ERK (Cell Signaling Technology, Beverly, MA) or total ERK (Sigma-Aldrich, Hercules, CA). The membranes were washed three times in PBS/0.1\% Tween-20 (PBS-T) and then incubated $1 \mathrm{~h}$ with secondary goat anti-rabbit antibody conjugated to horseradish peroxidase (Pierce Biotechnology Inc., Rockford, IL). Filters were subsequently washed in PBS-T and developed using chemiluminescence Western blotting detection reagents (Pierce Biotechnology Inc.).

Assessment of apoptosis. Loss of mitochondrial membrane potential $(\Delta \Psi \mathrm{m})$, a hallmark of the intrinsic apoptotic pathway, was detected by incubating living cells with tetramethylrhodamine ethyl ester (TMRE) (Invitrogen), as previously described (18) Activation of all caspases was assessed using FAM-VAD-FLICA (fluorochrome inhibitors of caspases, Chemicon International, USA). Samples were analysed on a FACSCalibur flow cytometer (Becton-Dickinson, Sweden) using the CellQuest software.

For the Bcl-2 overexpression studies, DU145 cells were transiently transfected with $1 \mu \mathrm{g}$ of either pCDNA3 or pBcl-2 plasmid by using Lipofectamine 2000 according to the manufacturer's specifications. DU145 cells were transfected for $16 \mathrm{~h}$ followed by treatment with $20 \mu \mathrm{M}$ sorafenib for $24 \mathrm{~h}$. Apoptosis was assessed by using Annexin V FLUOS kit (Roche Diagnostics Gmbh, Mannheim, Germany) according to the manufacturer's specifications and measure by using the FACS Calibur flow cytometer (Becton-Dickinson) and the CellQuest software.

Assessment of autophagy. Monodansylcadaverine (MDC) was used to visualize autophagic vacuoles. A stock solution of MDC solved in methanol was kept frozen at a concentration of $100 \mathrm{mM}$. The cells were cultured in $5 \mathrm{ml}$ dishes (Falcon) and incubated with $37 \mu \mathrm{M}$ sorafenib for $48 \mathrm{~h}$. MDC at a final concentration of $50 \mu \mathrm{M}$ was added to the cells for $1 \mathrm{~h}$ and kept in a $37^{\circ} \mathrm{C}$ incubator with humidified air and $5 \% \mathrm{CO}_{2}$. The dishes with cells were carefully washed with PBS and fixed with $4 \%$ paraformaldehyde for $20 \mathrm{~min}$ in the dark. A coverslip was mounted on the cells before analyzing with a Axioplan 2 imaging microscope (Zeiss) equipped with Chroma UV filter set $1100 \mathrm{v} 3$ excitation $325-375 \mathrm{~nm}$ (Chroma Technology). Images were obtained with an AxioCam MRm camera (Zeiss). 


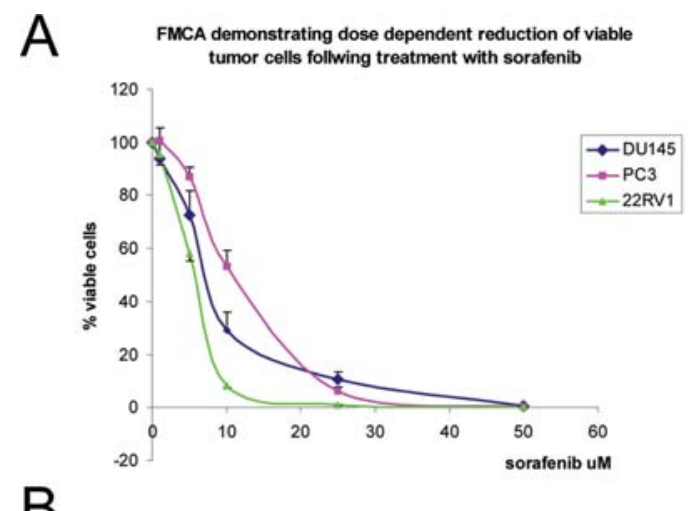

$\mathrm{B}$
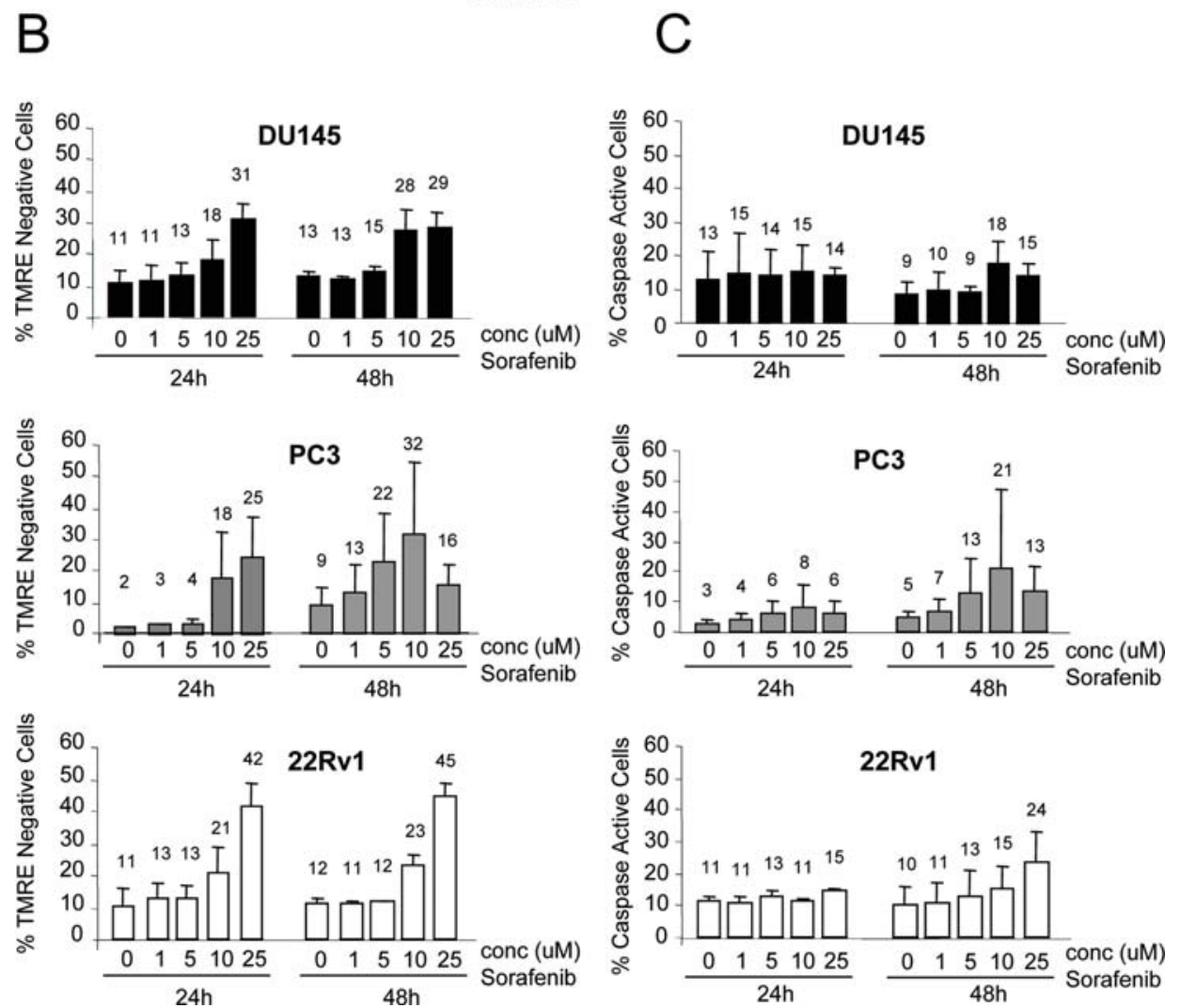

Figure 2. Sorafenib induces apoptosis in prostate cancer cell lines. (A) FMCA (fluorometric microculture cytotoxic assay) description. (B) The bars show the percentage of TMRE-negative cells, i.e. cells with reduced $\Delta \Psi \mathrm{m}$. Cells were treated with the indicated concentrations of sorafenib for 24 and $48 \mathrm{~h}$ before TMRE staining followed by FACS analysis. Error bars represent standard deviations of three independent experiments. (C) The bars show the percentage of FLICA-positive cells, i.e. cells with active caspases. The same experiment as in (B) was performed and the fraction of cells with active caspases in each sample was assessed using FAM-VAD-FLICA staining (pan-caspase) followed by FACS analysis. Error bars represent standard deviations of three independent experiments.

For the LC3-GFP experiments, DU145 cells were transfected by $4 \mu \mathrm{g}$ of pEGFP-LC3 plasmid (kind gift from Dr T. Yoshimori and Dr N. Mizushima from National Institute of Genetics, Mishima-Shizuoka, Japan) using Lipofectamine 2000 (Invitrogen) based on manufacturer's recommendation. Twenty-four hours after transfection the growth media were replaced by complete RPMI-1640 supplemented with $1 \mathrm{mg} / \mathrm{ml} \mathrm{G} 418$ (Sigma) for selection. EGFP-LC3 positive cells were selected by MoFlo ${ }^{\mathrm{TM}}$ XDP Cell Sorter (Beckman Coulter) and cultured for 3 weeks under G418 selection pressure. Following treatment, the cells were fixed with $4 \%$ PFA and mounted using Vectashield with DAPI. The images were recorded on a Zeiss Axioplan 2 microscope with a Zeiss dual mode cooled CCD camera and Axiovision software 4.1.

\section{Results}

Sorafenib inhibits ERK phosphorylation in prostate cancer cell lines. To evaluate the effect of sorafenib on the MAPK pathway in prostate cancer, changes in the phosphorylation levels of ERK1/2 proteins were analysed by Western blotting. Serum starved DU145 and 22Rv1 cells were incubated with FBS (fetal bovine serum) enriched medium in the absence or presence of sorafenib at the concentrations: 0,5, 10 and $25 \mu \mathrm{M}$. Sorafenib dose-dependently inhibited ERK1/2-phosphorylation in both cell lines (Fig. 1). In 22Rv1 cells, sorafenib completely inhibited ERK1/2-activation at the concentration of $5 \mu \mathrm{M}$, whereas in DU145 cells doses higher than $10 \mu \mathrm{M}$ were required for complete inactivation of the MAPK pathway. Total ERK levels were unchanged. 


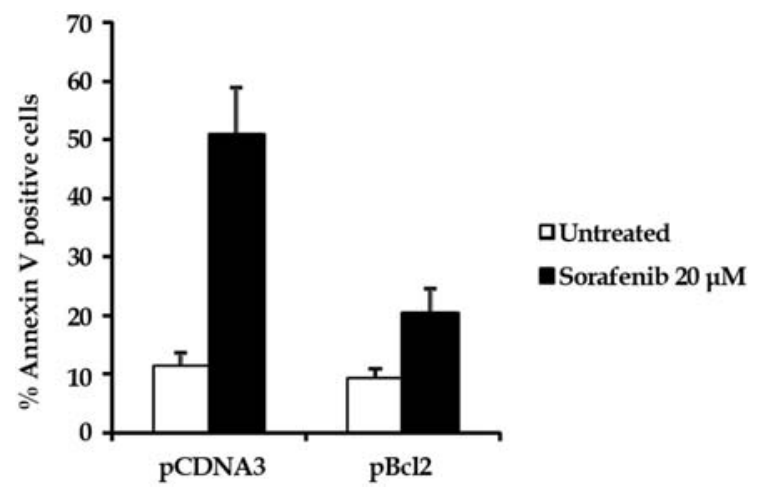

Figure 3. Bcl-2 overexpression inhibits sorafenib-induced cell death. DU145 cells were transiently transfected with either an empty vector pCDNA3 or a $\mathrm{Bcl}-2$ expressing vector for $24 \mathrm{~h}$ prior to treatment with $20 \mu \mathrm{M}$ sorafenib for additional $24 \mathrm{~h}$. The percentage of Annexin V positive cells was measured by Annexin V staining followed by FACS analysis. Error bars represent standard deviations of two independent experiments.

Sorafenib induces apoptosis in prostate cancer cell lines. Incubation with sorafenib for $72 \mathrm{~h}$ caused a dose-dependent decrease in cell viability in all three cell lines tested (Fig. 2A). $22 \mathrm{Rv} 1$ was the most sensitive cell line and at $10 \mu \mathrm{M}$ only $8.1 \%$ of the cells were viable compared to 29.1 and $53.2 \%$ for DU145 and PC3 cells, respectively. The DU145 cell line showed an intermediate sensitivity and PC3 cells were the least sensitive cell line compared to the other two at concentrations below $25 \mu \mathrm{M}$. Sorafenib $(50 \mu \mathrm{M})$ almost completely eradicated the viable cells, demonstrated by less than $0.5 \%$ remaining viable cells in all three cell lines.

We next investigated if apoptosis is responsible for the sorafenib-induced reduction of viable prostate cancer cells. To assess apoptosis TMRE and FAM-VAD-FLICA analysis were performed detecting reduction in mitochondrial membrane potential ( $\Delta \Psi \mathrm{m})$ (Fig. 2B) and active caspases (Fig. 2C), respectively.

Sorafenib treatment of DU145, PC3 and 22Rv1 cells for up to $48 \mathrm{~h}$ showed that the cells die by apoptosis although to different extent (Fig. 2B and C). Sorafenib dose-dependently induced TMRE-negative and FLICA-positive cells. The 22Rv1 cell line showed the highest number of apoptotic cells.

Sorafenib-induced apoptosis was furthermore inhibited by overexpressing the anti-apoptotic Bcl-2 protein in DU145 cells. DU145 cells were transfected with either an empty vector or a Bcl-2 expressing vector followed by treatment with $20 \mu \mathrm{M}$ sorafenib for $24 \mathrm{~h}$. Bcl-2 overexpression potently inhibited sorafenib-induced cell death (Fig. 3).

Sorafenib induces autophagy in prostate cancer cell lines. We have previously shown that MDC correlates well with other autophagic markers such as LC3-GFP staining and LC3 lipidation visualised by immunoblotting (19). Cells treated with $25 \mu \mathrm{M}$ sorafenib for $48 \mathrm{~h}$ were stained with MDC and analyzed by microscopy (Fig. 4A and B). MDC staining increased at $48 \mathrm{~h}$ following sorafenib treatment (Fig. 4A) which is indicative for autophagy.

DU145 cells stably expressing LC3-GFP were generated to further investigate sorafenib-induced autophagy. Treatment of DU145 with $20 \mu \mathrm{M}$ sorafenib for $24 \mathrm{~h}$ altered the diffuse cytoplasmic localisation of LC3-GFP into punctated staining

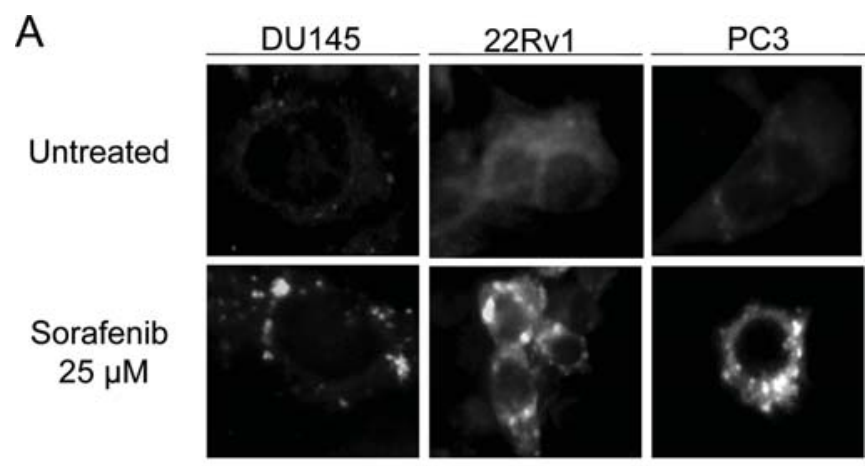

B

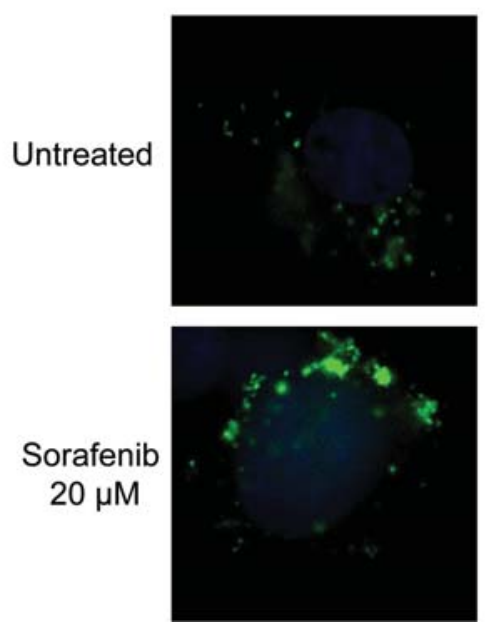

Figure 4. Sorafenib induces autophagy. (A) MDC staining of DU145, 22Rv1 and PC3 cells treated with $25 \mu \mathrm{M}$ sorafenib for $48 \mathrm{~h}$. The autophagolysosomes were visualised with Axioplan-2 microscope and Axiovision software. (B) Immunofluorescence image of DU145 cells stably expressing LC3-GFP and treated with $20 \mu \mathrm{M}$ sorafenib for $24 \mathrm{~h}$. The images were recorded on a Zeiss Axioplan-2 microscope and Axiovision software. The image is representative for at least three separate stainings.

characteristic of autophagosome formation (Fig. 4B). These data, in combination with the MDC stainings support our notion that sorafenib is inducing autophagy as well as apoptosis.

\section{Discussion}

The development of new treatment strategies for patients with metastatic AIPC remains a challenge. During the last year, several clinical trials have reported various degrees of clinical benefits following treatment with TKIs for this patient category (11-13,20,21). Sorafenib has demonstrated some clinical effects in three independent phase II trials in patients with hormone refractory, metastatic prostate cancer (11-13); however the underlying molecular sorafenib-induced antitumoral effects are poorly studied for this disease. The study by Dahut et al concerned mostly clinical effects following sorafenib treatment on progressive hormone refractory patients, however, some cellular studies were reported on the hormonesensitive LNCaP cell line (12). It was shown that sorafenib treatment increase PSA secretion for these cells and this phenomenon was suggested to be related to a drug-induced PSA transcriptional activity. It can be discussed how preclinical data on a hormone sensitive cell line translates into the 
clinical situation on patients with hormone-refractory disease. Nevertheless, 2 of 22 patients met PSA progression criteria but were found to have dramatic reduction of bone metastases on bone scan, which indicates the limitations of PSA as a marker of sorafenib treatment. Except from the data by Dahut et al regarding LNCaP cells, no study has addressed the effects of sorafenib on prostate cancer cells in vitro.

In this study, we evaluated the effects of sorafenib treatment on three well characterized cell lines PC3, DU145 and $22 \mathrm{Rv} 1(15,16)$. Two of these cell lines are known as hormone refractory, PC3 and DU145 and one as hormone-responsive, $22 \mathrm{Rv} 1$. We show that sorafenib treatment induced a clear dose-dependent reduction of the viable cell number for all three cell lines, with $22 \mathrm{Rv} 1$ cells being the most sensitive (Fig. 2A). Furthermore, we show that ERK1/2 activation was inhibited in a dose-dependent manner for both the hormone refractory cell line DU145 and the hormone-responsive cells, 22Rv1 (Fig. 1). These results verify that the effects on the MAPK pathway observed on other cell lines such as colon (12) pancreas and breast cancer cells (4), but not non-small cancer cell lines (4), are also valid on prostate cancer cells. Furthermore, and consistent with the inhibition of MAPK signaling, sorafenib induced apoptosis in all cell lines in a dose-dependent manner, as demonstrated by independent methods; reduction in mitochondrial membrane potential and induction of pan-caspase activity (Fig. 2B and C). Importantly, Bcl-2 overexpression protected DU145 cells from sorafenibinduced cell death (Fig. 3). In addition, a novel effectormechanism of sorafenib-treatment was demonstrated; induction of autophagy (Fig. 4A and B). Although autophagy was originally identified as a response to starvation, increasing amount of evidence shows that this process in fact is induced by various stress conditions such as hormone treatment, starvation and virus infections (22-24). Autophagic cell death is separated from apoptosis by the presence of autophagosomes and autophagolysosomes in the dying cells $(25,26)$ and autophagic cells have intact nuclei until the last phase of cell death. This way of dying has been termed type II programmed cell death in recent years (27). Moreover, data indicate that autophagy and apoptosis pathways exert overlapping functions and share regulatory components; for example blockage of autophagic signaling increased apoptosis whereas inhibition of apoptosis resulted in autophagic cell death (28-30). To our knowledge, this study is the first to demonstrate induction of autophagy in prostate cancer cell lines following treatment with the TKI sorafenib. A potential mechanism is the inhibitory properties of sorafenib on tyrosine kinase receptors such as PDGFR and VEGFR $(31,32)$. Both of these receptors will activate PI3K signaling and downstream of this also mTOR. Potentially inhibition of this signaling could instead trigger autophagy through decreased mTOR activity.

Imatinib, another multiple TKI known to target c-abl, Arg kinases, PDGFR-a and b, c-kit and c-fms has recently been shown to induce autophagy in mammalian cells (33). It is possible that shared downstream signaling targets, such as PI3K among several, which are blocked by both imatinib and sorafenib is the reason that both these drugs induce autophagy. In the present study DU145 cells displayed the most prominent autophagic pattern as judged by MDC stainings and in cells overexpressing a GFP tagged form of one of the classical markers of autophagy, namely LC3. The importance of autophagy in sorafenib-induced cell death of the prostate cancer cell lines is not clear and thereby a subject of intense investigation in our laboratory. It will be interesting to identify whether autophagy promotes the sorafenib-induced cytotoxic effects or it prevents them.

It is noteworthy that treatments targeting steroid hormone receptors, such as anti-androgen, estrogens and glucocorticoids all may induce cell death with autophagic features (22-24). Considering the link between prostate cancer and androgens one may speculate that sorafenib-induced autophagy could alter the cellular sensitivity to anti-androgen based treatment. As mentioned above, a number of different cell death inducing agents have recently been shown to cause cell death with autophagic features. An ongoing debate in the literature is whether the autophagy under such circumstances is a protective mechanism reducing drug induced cell death, or whether it aids in the killing of cells. Recent data on TKIs suggest that autophagy protects cells from the cytotoxic properties of the TKIs. For example, Mishima et al, recently demonstrated that inhibition of autophagy reverts the resistance of leukemic cells to another TKI, imatinib (34). Whether autophagy, induced by sorafenib in prostate cancer cells is cytoprotective or cytotoxic remains to be defined in future studies.

In summary, we demonstrate that sorafenib treatment significantly affects cell viability of prostate cancer cell lines in a dose-dependent manner. Furthermore, the MAPK pathway is inactivated and apoptosis induced. Importantly, we also show, to our knowledge for the first time, that sorafenib treatment induces cellular autophagy of prostate cancer cells. This feature is in accordance with the anticancer potential of sorafenib and adds another important effector mechanism to this compound. Although the relationship between cell death and autophagy is not yet clear, our results open potential treatment combinations that may augment the effect of sorafenib. Super-additive effects may be achieved by combining sorafenib either with drugs that promote autophagy, for example the rapalogues, or by combining sorafenib with compounds that specifically inhibit the autophagic process.

\section{Acknowledgements}

This study was supported by grants from Swedish Cancer Society Grant, King Gustav V's Jubilee Fund, Cancer Society in Stockholm.

\section{References}

1. Tannock IF, de Wit R, Berry WR, et al: Docetaxel plus prednisone or mitoxantrone plus prednisone for advanced prostate cancer. N Engl J Med 351: 1502-1512, 2004.

2. Petrelli A and Valabrega G: Multitarget drugs: the present and the future of cancer therapy. Expert Opin Pharmacother 10: 589-600, 2009.

3. Ravaud A, Wallerand H, Culine S, et al: Update on the medical treatment of metastatic renal cell carcinoma. Eur Urol 54: 315-325, 2008.

4. Wilhelm SM, Carter C, Tang L, et al: BAY 43-9006 exhibits broad spectrum oral antitumor activity and targets the RAF/ MEK/ERK pathway and receptor tyrosine kinases involved in tumor progression and angiogenesis. Cancer Res 64: 7099-7109, 2004. 
5. Mendel DB, Laird AD, Xin X, et al: In vivo antitumor activity of SU11248, a novel tyrosine kinase inhibitor targeting vascular endothelial growth factor and platelet-derived growth factor receptors: determination of a pharmacokinetic/ pharmacodynamic relationship. Clin Cancer Res 9: 327-337, 2003.

6. Ferrara N: The role of vascular endothelial growth factor in pathological angiogenesis. Breast Cancer Res Treat 36: 127-137, 1995.

7. Bettencourt MC, Bauer JJ, Sesterhenn IA, Connelly RR and Moul JW: CD34 immunohistochemical assessment of angiogenesis as a prognostic marker for prostate cancer recurrence after radical prostatectomy. J Urol 160: 459-465, 1998.

8. Erlich S, Tal-Or P, Liebling R, et al: Ras inhibition results in growth arrest and death of androgen-dependent and androgenindependent prostate cancer cells. Biochem Pharmacol 72: 427-436, 2006.

9. Gioeli D: Signal transduction in prostate cancer progression. Clin Sci 108: 293-308, 2005.

10. Gioeli D, Mandell JW, Petroni GR, Frierson HF Jr and Weber MJ: Activation of mitogen-activated protein kinase associated with prostate cancer progression. Cancer Res 59: 279-284, 1999.

11. Chi KN, Ellard SL, Hotte SJ, et al: A phase II study of sorafenib in patients with chemo-naive castration-resistant prostate cancer. Ann Oncol 19: 746-751, 2008.

12. Dahut WL, Scripture C, Posadas E, et al: A phase II clinical trial of sorafenib in androgen-independent prostate cancer. Clin Cancer Res 14: 209-214, 2008.

13. Steinbild S, Mross K, Frost A, et al: A clinical phase II study with sorafenib in patients with progressive hormone-refractory prostate cancer: a study of the CESAR Central European Society for Anticancer Drug Research-EWIV. Br J Cancer 97: 1480-1485, 2007.

14. Colloca G, Checcaglini F and Venturino A: About sorafenib in castration-resistant prostate cancer. Ann Oncol 19: 1812-1813; author reply 1813-1814, 2008.

15. Alimirah F, Chen J, Basrawala Z, Xin H and Choubey D: DU-145 and PC-3 human prostate cancer cell lines express androgen receptor: implications for the androgen receptor functions and regulation. FEBS Lett 580: 2294-2300, 2006.

16. Sramkoski RM, Pretlow TG II, Giaconia JM, et al: A new human prostate carcinoma cell line, 22Rv1. In Vitro Cell Dev Biol Anim 35: 403-409, 1999.

17. Larsson R, Kristensen J, Sandberg C and Nygren P: Laboratory determination of chemotherapeutic drug resistance in tumor cells from patients with leukemia, using a fluorometric microculture cytotoxicity assay (FMCA). Int J Cancer 50: 177-185, 1992.

18. Panaretakis T, Pokrovskaja K, Shoshan MC and Grander D: Activation of Bak, Bax, and BH3-only proteins in the apoptotic response to doxorubicin. J Biol Chem 277: 44317-44326, 2002.

19. Laane E, Tamm KP, Buentke E, et al: Cell death induced by dexamethasone in lymphoid leukemia is mediated through initiation of autophagy. Cell Death Difffer (In press).
20. Gravis G, Bladou F, Salem N, et al: Results from a monocentric phase II trial of erlotinib in patients with metastatic prostate cancer. Ann Oncol 19: 1624-1628, 2008.

21. Sonpavde G, Hutson TE, Berry WR, Boehm KA and Asmar L: Phase II trial of sunitinib for the therapy of progressive metastatic castration-refractory prostate cancer after previous docetaxel chemotherapy. Clin Genitourinary Cancer 6: 134-137, 2008.

22. Bursch W, Ellinger A, Kienzl H, et al: Active cell death induced by the anti-estrogens tamoxifen and ICI 164384 in human mammary carcinoma cells (MCF-7) in culture: the role of autophagy. Carcinogenesis 17: 1595-1607, 1996.

23. Herman-Antosiewicz A, Johnson DE and Singh SV: Sulforaphane causes autophagy to inhibit release of cytochrome C and apoptosis in human prostate cancer cells. Cancer Res 66: 5828-5835, 2006.

24. Lum JJ, DeBerardinis RJ and Thompson CB: Autophagy in metazoans: cell survival in the land of plenty. Nat Rev 6: 439-448, 2005.

25. Bursch W, Ellinger A, Gerner C, Frohwein U and SchulteHermann R: Programmed cell death (PCD). Apoptosis, autophagic PCD, or others? Ann N Y Acad Sci 926: 1-12, 2000.

26. Bursch W, Hochegger K, Torok L, Marian B, Ellinger A and Hermann RS: Autophagic and apoptotic types of programmed cell death exhibit different fates of cytoskeletal filaments. J Cell Sci 113: 1189-1198, 2000.

27. Kroemer $G$ and Levine B: Autophagic cell death: the story of a misnomer. Nat Rev 9: 1004-1010, 2008.

28. Boya P, Gonzalez-Polo RA, Casares N, et al: Inhibition of macroautophagy triggers apoptosis. Mol Cell Biol 25: 1025-1040, 2005.

29. Jia L, Dourmashkin RR, Allen PD, Gray AB, Newland AC and Kelsey SM: Inhibition of autophagy abrogates tumour necrosis factor alpha induced apoptosis in human T-lymphoblastic leukaemic cells. Br J Haematol 98: 673-685, 1997.

30. Shimizu S, Kanaseki T, Mizushima N, et al: Role of Bcl-2 family proteins in a non-apoptotic programmed cell death dependent on autophagy genes. Nat Cell Biol 6: 1221-1228, 2004.

31. Andrae J, Gallini R and Betsholtz C: Role of platelet-derived growth factors in physiology and medicine. Genes Dev 22: 1276-1312, 2008.

32. Ferrara N, Gerber HP and LeCouter J: The biology of VEGF and its receptors. Nat Med 9: 669-676, 2003.

33. Ertmer A, Huber V, Gilch S, et al: The anticancer drug imatinib induces cellular autophagy. Leukemia 21: 936-942, 2007.

34. Mishima Y, Terui Y, Taniyama A, et al: Autophagy and autophagic cell death are next targets for elimination of the resistance to tyrosine kinase inhibitors. Cancer Sci 99: 22002208, 2008. 